\title{
Sarcastic Expressions in Two American Movies
}

\author{
Emhasib Sandi Bachtiar*, Tofan Dwi Hardjanto \\ Universitas Gadjah Mada, Indonesia \\ *Email: emhasib.sandi@ugm.ac.id
}

\begin{abstract}
A B S T R A C T
This study investigates the sarcastic utterances found in two American movies. The data for the research were dialogues containing sarcastic expressions found in the movies Fantastic Four (2005) and its sequel Fantastic Four: Rise of the Silver Surfer (2008). The data were analyzed and categorized according to their forms using Camp's theory (2011). The sarcastic utterances were also classified according to their functions using Leech's theory (1983). The results indicate that in terms of form, illocutionary sarcasm (60\%) was most frequently used by the characters in the movies, which suggests that the characters in the movies tend to express their sarcasm through illocutions. In terms of function, sarcasm in the movies was more commonly $(56 \%)$ used for collaborative purposes. The results of the research also suggest that there has to be a clear context in understanding sarcastic expressions, and the interlocutors must share some sufficient common ground in employing sarcasm.
\end{abstract}

Keywords: sarcasm, expressions, illocutionary functions, common ground.

\section{INTRODUCTION}

Sarcasm is an important aspect in daily communication. It is traditionally understood as something which means the opposite of what is said. In expressing sarcasm, the speakers hide their true intention by saying the contrary of what they really mean. Caucci and Kreuz (2012, p. 1) argue that a listener has to infer a sarcastic utterance on more than one level, because like many types of figurative language, it does not always have the clear intended meaning. Sarcasm can also be used as one way to express a negative emotion toward others. Furthermore, sarcasm can be used for humorous purposes (p. 2). Their research results show that a sarcastic utterance can be both negative and funny at the same time. Moreover, in answering why people tend to use sarcasm to hide their true meanings rather than say it directly, Dews, Kaplan \&Winner (1995) propose that some of the main reasons are "to be funny, to soften the edge of an insult, to show themselves to be in control of their emotions, and to avoid damaging their relationship with the addressee" (p. 347).

In order to understand a sarcastic utterance, the speaker and the hearer must share a common ground of knowledge. Consider two friends are talking, and A makes a joke which $\mathrm{B}$ does not think it is funny at all, then B responds with "That is very funny!" If $A$ and $B$ are not in the same ground of knowledge in this case, then A would fail in interpreting B's response as sarcasm. Caucci and Kreuz (2012, p. 2) explain that there are two steps in understanding a sarcastic utterance: First, the listener must recognize that the utterance is not literally true. Second, the listener must infer the speaker's true intention, which in this case B does not really think that A's joke is funny, instead he gives him a sarcastic response by saying the opposite of what he really means. Therefore, having a common ground between the speaker and the hearer is necessary in understanding sarcasm, or otherwise there will be a misunderstanding between them. Below is 
another example of sarcastic expression taken from Fantastic Four (2005).

(1) Ned: Well, Victor, the bank would like to congratulate you on the fastest freefall since the Depression. We can't even give your stock away.

Victor: Ned, you know I can turn this around.

In the example above, Ned as the sponsor of Victor's research project congratulates him for aborting his mission in space. Ned is disappointed with Victor because the mission does not go as they planned, and he expressess his feeling sarcastically rather than telling Victor what he really feels directly. Furthermore, Ned's utterance becomes sarcastic because Victor's failure is not supposed to be rewarded. In this case, if Ned and Victor as a co-worker do not share the common ground and the same understanding, Victor would mislead Ned's intention.

As sarcasm plays an important role in daily communication, especially in English, a number of attempts have been made to study it from different points of view. Cheang and Pell (2007), for example, examine the sound of sarcasm by doing an acoustic analysis for mean fundamental frequency (F0), F0 standard deviation, F0 range, mean amplitude, amplitude range, speech rate, harmonics-to noise ratio (HNR, to probe for voice quality changes), and one-third octave spectral values (to probe resonance changes), in a speech recorded by a group of native English speakers. The results indicate that "sarcasm is reliably characterized by a number of prosodic cues, although one acoustic feature appeared particularly robust in sarcastic utterances: overall reductions in mean $\mathrm{F} 0$ relative to all other target attitudes" (Cheang and Pell, 2007, p. 366). Cheang and Pell (2007, p. 366) therefore, conclude that "sarcasm in speech can be characterized by a specific pattern of prosodic cues in addition to textual cues, and that these acoustic characteristics can be influenced by language used by the speaker" (p. 366).

Minchin (2010) also conducts a research on sarcasm focusing on the expression of sarcasm in the Odyssey. By having a more advanced understanding towards sarcasm in contemporary world, in her research, Minchin (2009) tries to view the features of sarcastic talk in the Odyssey and in contemporary world. The results reveal that many features of the spoken exchanges of the second half of the Odyssey are in common with the sarcastic talk in contemporary world (Minchin, 2009, p. 533). She demonstrates that Homer "used sarcastic talk to shape character, to establish mood, and to give structure to the scenes" (Minchin, 2009, p. 533).

Another study by Bowes and Katz (2011) examined sarcasm by using realistic conversational format. In this method, the participants are asked to read either a sarcastic or a non-sarcastic aggressive argument between same-gendered interlocutors, and rate the pragmatic goals being expressed using a range of measures taken from previous studies (Bowes and Katz, 2011, p. 215). Bowes and Katz (2011) group the factor analysis into separated factors: one is called "victimization" and the other is called "relational aggresion". The results show that the sarcastic version is perceived as more victimizing and more relationally aggressive, while the secondary analyses demonstrate that participants perceive the negative comment of the aggressor as more humorous and less aggressive when taking the perspective of the aggressor than when taking the perspective of the victim (Bowes and Katz, 2011, p. 215).

Unlike the previous studies, Prabowo (2013) investigated the forms and functions of sarcastic expressions found in the movie The Guard. He adopts Camp's theory (2011) to classify the sarcastic utterances, and Leech's theory (1983) to investigate the functions of the sarcastic utterances. From seventeen occurrences of sarcastic expressions found in the movie, only two types of sarcasm were discovered: six belonged to propositional sarcasm, and eleven to illocutionary sarcasm (Prabowo, 2013, p. 19). Then, in terms of functions, sarcasm was used for competitive, convivial, and collaborative functions (p. 36). Prabowo (2013) concluded that sarcasm is not just a simple meaning inversion, but also involves adequate context, intention from the speaker, and response from the hearer (p. 41). 
Cahyani (2017) investigated sarcasm in the TV series The Big Bang Theory. In her study, Cahyani examined not only the conversational maxims which were flouted in the sarcastic utterances found in the series, but also the purposes of those sarcastic utterances. The results show that all four maxims are flouted by the characters in the series, with the maxim of quality becoming the most frequently flouted maxim (72.34\%). In addition, sarcasm was commonly used for sophistication or humorous purposes (25.53\%) (Cahyani, 2017).

This paper investigates sarcastic expressions in two American movies: Fantastic Four (2005) movie and its sequel, Fantastic Four: Rise of the Silver Surfer (2008). These two movies are about a group of people who get their super power from the accident of strange cosmic radiation in space. Caucci and Kreuz (2012) argue that the amount of common ground might influence people to express themselves sarcastically (p. 3). Since the main characters of these movies are a group of close friends, it is very likely that sarcastic expressions are used in their communication.

It is interesting to investigate how people prefer to use sarcasm rather than just being straightforward in expressing their feeling, especially when it happens between friends. Thus, a group of friends as the main characters in the movies support this reseach to see how common ground affect people in using sarcasm. This aspect also makes this paper different from the previous studies done by Prabowo (2013) and Wulandari (2017). Prabowo (2013) focuses mainly on the sarcastic expressions produced by two main characters in the British movie The Guard, while Wulandari (2017) focuses only on the sarcasm produced by one British character in the movie Letters to Juliet.

\section{THEORETICAL FRAMEWORK}

\section{Speech Acts}

As a medium of communication, language is used to transfer messages through utterances. Those utterances produced by a speaker perform some actions, which are known as speech acts. According to Yule (1996, p. 47), a speech act is an action performed by using an utterance. It can be understood that when someone says something, he does not only produce utterances with grammatical structure, but also carries some actions. For example, when an utterance is produced, the speaker can perform an act of stating a fact or opinion, apologizing, denying, or asking for something.

Austin (1962, p. 108) identifies three levels of a speech act: locutionary, illocutionary, and perlocutionary act. To illustrate what they mean, below is a conversation between Reed and Sue taken from Taken from Fantastic Four: Rise of the Silver Surfer (2008).

(2) Sue: I have a fitting in half an hour. The musicians after that. I haven't picked out the place settings or the flowers. There's too much to do.

Reed: Don't worry about it. Between the two of us, we'll get it all done.

\section{Sue: And what were you doing when I walked in?}

The first level, locutionary act, is the act of saying something. In the example above, "I have a fitting in half an hour...", "Don't worry about it...", "And what were you doing...". These are the locution, i.e., the words themselves. Then, what the speakers are doing with those words is called Illocutionary act. In the example above, Sue is 'complaining', and Reed is 'promising'. Both are simply expressing intentions about their own action. This specific purpose that the speaker has in mind is also called illocutionary force. The last level is perlocutionary act. Austin (1962, p. 118) explains that perlocutionary act is what we achieve by saying something, e.g. convincing, persuading, etc. This act refers to the relation between utterance and its effect on the hearer. This effect which comes up from the speaker's uttered speech act is also known as perlocutionary effect. For instance, in (2), Reed is convincing Sue that they will get everything done as the reaction to Sue's complaint. Reed's reaction to Sue's sarcastic comment is also considered as perlocutionary effect.

Yule (1996) also explains that there are two types of speech act, i.e. direct and indirect speech 
act. A direct speech act happens whenever there is a direct relationship between a structure and a function. Otherwise, when there is an indirect relationship between those two, it is known as indirect speech act (p. 55). For illustration, below are some examples of a mother talking to her son about his messy bedroom:

(3a) Clean your room!

(3b) Don't you think you have to clean your room?

(3c) Your room looks like a mess.

(3d) Thank you for cleaning your room this morning.

The structures above are used to accomplish the same basic function, i.e., the mother wants her son to clean his bedroom. Even though the basic function of all the four utterances is a command, only (3a) is considered as a direct speech act. Utterance (3b) has an interrogative structure which is used as question; therefore, it is an indirect speech act. Then, the declarative structure in (3c) and the imperative in (3d) are used as an indirect request. Moreover, the utterance in (3d) sounds more sarcastic because it is used as a verbal aggression to evaluate her son's attitude. For that reason, sarcasm belongs to an indirect speech act because there is always an indirect relationship between what the speakers say and what the speakers mean by their words. On this, McDonald (1999) argues that "sarcasm is an indirect form of speech intentionally used to produce a particular dramatic effect on the listener" (p. 486).

However, an indirect speech act requires the hearer to interpret the actual meaning or intention of what the speaker has said. If the hearer failed to do so, there would be a misunderstanding between the interlocutors.

\section{Context}

Yule (1996, p. 3) states that "pragmatics has more to do with the analysis of what people mean by their utterances, rather than the words themselves". Therefore, to know what the speaker's aim in saying those utterances, we need context, as it provides the time and place in which the words are uttered (Cutting, 2002, p.2). In addition, Yule (1996) also says that "pragmatics is the study of contextual meaning".

Moreover, understanding the context is the easiest way that the hearer can do to recognize a sarcastic utterance. Brant (2012) argues that "sarcasm involves the expression of an insulting remark that requires the interpreter to understand the negative emotional connotation of the expresser within the context of the situation at hand" (p. 145). When the context is clear, the addressee will realize that there is an incoherence between what the speaker says and the actual situation. For that reason, context becomes the main cue to perceive sarcasm and it takes an important role in this research.

Cutting (2002, p. 3-15) divides context into three types: a) Situational context, which refers to what the speakers know about what they can see around them. It also includes the situation in which the interaction is occurring. b) Background knowledge context, which refers to what the interlocutors know about each other and the world. Cutting (2002) also explains that the background knowledge context covers two types, i.e. cultural and interpersonal. Cultural refers to what the interlocutors understand as the general knowledge about the areas of life, and interpersonal refers to the private knowledge about their own history. c) Co-textual context, which is what the speaker and the hearer know about what they have been saying.

The example below, taken from Fantastic Four: Rise of the Silver Surfer (2008), illustrates the importance of context in analyzing an utterance:

(4) Johnny: You know, I'm not exactly a deep kind of guy.

\section{Ben: Really?}

If we do not know the context of the dialogue above, we cannot understand what Ben really means by his utterance. The conversation above happens at one night in a bar, where Ben and Johnny are talking about the end of the world and Johnny's desire to find true love like Ben does. This is known as the situational context. Then, the background of knowledge context in (4) is Ben's private knowledge as Johnny's best friend that he 
is not a deep kind of person at all. Even without mentioning it, Ben has known this fact for a long time, and this information is not something new. From this context, we can already see Ben's intention by pretending to be surprised about Johnny's statement. Thus, by knowing the context, it helps us to understand what is being assaulted, its reason, and what the speaker really means.

\section{Sarcasm}

As mentioned earlier, sarcasm is traditionally understood as something which has the opposite meaning of what is said. MerriamWebster online dictionary defines sarcasm as "the use of words that mean the opposite of what you really want to say especially in order to insult someone, to show irritation, or to be funny". Furthermore, the interlocutors must share common ground in employing sarcasm. Caucci and Kreuz explain that friends are more successful at comprehending sarcasm than strangers (2012, p. $3)$.

According to Cutting, sarcasm is a form of irony that is not so friendly and it is usually intended to hurt (2002, p. 38). As cited in Joshi, Bhattacharyya \& Carman, 2017, p. 3) Giora (1995) argues that

Irony/sarcasm is a form of negation in which an explicit negation marker is lacking. In other words, when one expresses sarcasm, a negation is intended, without putting a negation word like 'not'.

However, there are some differences between irony and sarcasm, even though these terms are often mistaken as the same thing. According to Haiman (1998, p. 20), there are two important differences between sarcasm and irony:

First, situations may be ironic, but only people can be sarcastic. Second, people may be unintentionally ironic, but sarcasm requires intention. What is essential to sarcasm is that it is overt irony intentionally used by the speakers as a form of verbal aggression, and it may thus be contrasted with other aggressive speech acts, among them the put-on, direct insults, curses, vituperation, nagging, and condescension.

An example from the movie Fantastic Four (2005) below gives a clearer illustration about the difference between sarcasm and irony:

(5) Reed: You need to control yourself and think before you act.

Johnny: Yeah, but see, that's your problem. You always think, you never act. What if we got these powers for a reason? What if it's like some higher calling?

Reed: A higher calling? Like getting girls and making money?

\section{Johnny: Is there any higher?}

This conversation is ironic because Johnny believes that their power is a kind of calling from God to save the world, yet what he has been doing is just looking for fame, getting girls and money. Nevertheless, Reed responds sarcastically to him by using a like-prefixed sarcastic expression, emphasizing the fact that what Johnny has been doing is the opposite of what he believes.

In addition, Camp $(2011$, p. 2) proposes that sarcasm can be viewed from two different points, i.e. semanticism and expressivism. From the point of view of semanticism, sarcasm is semantically encoded at the level of logical form by an operator which 'inverts' the literal meaning of the word or clause to which it applies, whereas from the exxpressivism viewpoint, sarcasm is a matter of meaning at all, arguing instead that it serves to draw attention to a disparity between how things are and how they should be, and thereby expresses a "dissociative attitude" about some aspects of this disparity. Since the two arguments above put sarcasm in a different position, following Camp (2011), this research only used the semanticism point of view in classifying the data found.

\section{Common Ground}

As mentioned earlier, in employing sarcasm, the speaker and the hearer must share a common ground to comprehend what is actually being said. Clark (1992, p. 69) argues that the common 
ground between two people consists of their mutual knowledge, beliefs, and suppositions. To illustrate this, below is an example:

(6) Ben: (To Reed) Victor ain't that bad, huh. "He's just a little larger than life, right?" Maybe next time you'll listen to me before...

Ben's sarcastic argument above is used to assault Reed after Victor kidnaps and attacks him. Ben makes it as if he believes that what he says is true, while what he actually means is the opposite. In this dialogue, Ben believes that somehow Reed will understand his utterance because he knows that they share the same information and belief about Victor. This same information/common ground makes Reed understand what Ben's true intention is. In this event, there is one general principle of common ground which is applied when the speaker expresses his utterance, i.e., the principle of optimal design:

The speaker designs his utterance in such a way that he has good reason to believe that the addressees can readily and uniquely compute what he meant on the basis of the utterance along with the rest of their common ground (Clark, Schreuder \&Buttrick, 1983, p. 246).

Furthermore, Caucci and Kreuz (2012, pp. 3-4) also argue that according to the principle of inferability, when people share common ground, the speaker can infer that the hearer will be able to distinguish sarcastic intention from the literal one. Thus, common ground plays an important role in interpreting sarcastic utterances. Furthermore, the amount of common ground shared by two people can affect them to express themselves sarcastically. Hence, the more common ground that is shared by the interlocutors, the more possible the hearer to infer the sarcastic utterance.

In addition, Clark, Schreuder, and Buttrick (1983) propose that there are three sources of information in the common ground between two people:

The first is perceptual evidence, what the two have jointly experienced or are jointly experiencing at the moment. The second is linguistic evidence, what the two have jointly heard, said or are now jointly hearing as participants in the same conversation. The third is community membership. They take as common ground everything they believe is universally, or almost universally, known, believed, or supposed in the many communities and subcommunities to which they mutually believe they both belong (p. 247).

Thus, we can see that the type of common ground information in (6) is the perceptual evidence, because Ben and Reed had experienced how evil Victor was. It would be different if they were strangers, because the common ground might come from the conversation they were in or their joint membership in a community.

\section{METHODS}

The data for this research were collected from the movie Fantastic Four (2005) and its sequel, Fantastic Four: Rise of the Silver Surfer (2008). Both of these movies were watched from their original VCDs, which were distributed in Indonesia by PT. Inova Digimedia. These movies were chosen because the main characters are five friends who have close relationships, and according to Caucci and Kreuz (2012), friends are more successful in understanding each other's sarcasm than strangers.

There were three steps in collecting the data in this research. The first step was watching the original VCDs and downloading the subtitles from Www.subscene.com. After that, since the data were in the form of dialogues, the utterances which indicated sarcasm were observed and written in notes. Third, the context was explained to help understand about what was happening or the reason why the characters in the movie said a sarcastic expression.

The data which have been collected were classified into four classes (Camp, 2011: 2): propositional, lexical, like prefixed, and illocutionary sarcasm. The results were analyzed according to the characteristics of each category 
that have been explained by Camp (2011) to discover which category of sarcasm was used the most. Then, the illocutionary functions of the sarcastic expressions were also investigated and classified using Leech's theory (1983, p. 104) into collaborative, competitive, conflictive, and convivial functions.

Since the data were taken from two movies, the code of the movie was attached next to the timestamps; F1 for Fantastic Four (2005), and F2 for Fantastic Four: Rise of the Silver Surfer (2008). After that, the code for the types of sarcasm and the number of occurrences were also attached next to the movie's code: Pro for Propositional, Lex for Lexical, LP for Like-Prefixed and Ill for Illocutionary sarcasm. The number of occurences were followed by the categories of illocutionary functions as well: Col for Collaborative, Com for Competitive, Conv for Convivial, and Conf for Conflictive functions. Below is an example of how the data were coded:

$$
\text { 00:44:04,600 - 00:44:08,230 (F1.LP.01.Col) }
$$

Reed, Ben, Johnny and Sue are moving in to Reed's apartment to research their new powers. Before they get in to the elevator, Reed receives his apartment bills which have not been paid for nine years, and Sue accidentally sees them.

Reed: (to Sue) We had a tough year.

Ben: Yeah, like nine straight.

In the example above, the timestamp 00:44:04,600 - 00:44:08,230 shows the exact time the dialogue appears on the screen, and F1 stands for the movie where the dialogue from, i.e. Fantastic Four (2005). Next, LP stands for Like Prefixed sarcasm and 01 is the number of occurrence of this type. Then, the last code, which is Col, shows that the utterance has the collaborative function.

\section{RESULTS AND DISCUSSION}

\section{Types of Sarcasm}

Altogether 25 sarcastic expressions were found in the two movies which involve the main characters. As mentioned earlier, those sarcastic expressions are classified into four classes according to Camp (2011, p.2). The table below presents the frequency and distribution of the four types of sarcasm in the movies.

Table 1. The Frequency and distribution of sarcasm in the Movies

\begin{tabular}{|c|c|c|c|}
\hline No. & Sarcasm & Number & $\%$ \\
\hline 1. & Illocutionary & 15 & 60 \\
\hline & Lexical & 1 & 4 \\
\hline 3. & Like-Prefixed & 3 & 12 \\
\hline & Propositional & 6 & 24 \\
\hline & Total & 25 & 100 \\
\hline
\end{tabular}

The table shows that the most frequently used sarcasm is Illocutionary sarcasm, with 15 occurrences (60\%). Then, it is followed by Propositional sarcasm with six occurrences (24\%), and Like-Prefixed sarcasm with three occurrences $(12 \%)$. The table also shows that the least frequently used sarcasm type in the two movies is Lexical sarcasm which was used only once (4\%). These findings seem to suggest that the characters in the movies tend to express their sarcasm in the form of illocutionary sarcasm, and they do not seem to prefer to use lexical sarcasm in their utterances.

\section{Illocutionary Sarcasm}

The most distinctive point of Illocutionary sarcasm is that it targets a speech act with an illocutionary force rather than just an assertion (Camp, 2011, p. 32). This type of sarcasm is the most frequently used type of sarcasm in this research, with 15 occurrences (60\%). This means that more than half of the sarcastic utterances used in the movies belong to this type. Therefore, we can say that people in the two movies tend to put sarcastic expression in their illocutionary speech act. The example below illustrates the use of illocutionary sarcasm in the movies.

00:06:57,292 - 00:07:15,267 (F2.Ill.10.Com)

Sue is complaining to Reed because she has to do a lot of things for the wedding by 
herself, but Reed is too busy with his digital assistant and ignoring her.

Sue: I have a fitting in half an hour. The musicians after that. I haven't picked out the place settings or the flowers. There's too much to do.

Reed: Don't worry about it. Between the two of us, we'll get it all done.

\section{Sue: And what were you doing when I walked in?}

In this conversation, Sue pretends to ask a question in order to point out Reed's rudeness for being insensitive with their marriage preparation. Sue feels like she is the only one who has to do everything, while Reed is too busy with his science project. In this case, her purpose of asking the question is to express her evaluation of Reed's behavior, which is considered as rude. Moreover, when sarcasm is uttered in a question form, it does not demand an answer because the speaker already knows it from their evaluation. The fact that Sue gives sarcastic expression as a response to Reed's statement, which is not suitable with what he has been doing, makes the sarcasm easily detected because the context is clear. In addition, from 15 Illocutionary sarcasm found in this research, 6 of them are similar to example (1), where the speaker shows their pretense to give an evaluation by asking a question.

Another example of the use of illocutionary sarcasm is shown below. Tepperman, Traum \& Narayanan (2006) argue that the use of "yeah, right" can be interpreted as a sarcastic expression in agreement with interlocutor's previous statement, but it also functions as evidence of understanding that statement (p. 1839). More explanation can be seen through the examples below:

$$
\text { 00:50:35,908 - 00:50:42,330 (F2.Ill.15.Col) }
$$

After being forced to work with Victor, Reed is obsessed to find the best way to catch Silver Surfer and do better than Victor. Seeing Reed working too hard, Sue is trying to make Reed relax and get some rest, but Reed does not want to.
Sue: Reed, you're gonna find the answer. You always do.

Reed: Thanks, Sue.

Sue: You just need to relax.

Reed: Yeah, right.

In the example above, Reed responds to Sue's statement sarcastically as a pretense that he agrees with her, while he actually does not. This expression might seem sincere, but the context shows that Reed is already obsessed with his work and does not even want to get some rest as Sue suggested. Therefore, by saying "yeah, right" sarcastically, Reed pretends to approve that he will come up with the answer of his observation if he gets relax like Sue said, while he actually does not believe so.

\section{Lexical Sarcasm}

Camp (2011) explains that "lexical sarcasm most naturally targets expressions which denote the extreme end of a conventionally-associated, normatively-loaded scale, so that the sarcastic inversion contributes a value at the scale's extreme other end" (p. 25). It also targets only a single expression in an utterance. As the least frequently used type of sarcasm found in this research, there is only one dialogue which belongs to this class, as shown below:

(10) 00:34:33,840 - 00:34:37,880 (F1.Lex.01.Com)

Reed, Sue, and Johnny are trying to see Ben who is causing a traffic accident on the bridge, but they cannot get through the crowd. Then, Reed asks Sue to use her invisible power, but when she is taking her clothes off, her power disappears and people can see her naked.

Sue: ( To Reed) Any more great ideas? Why don't you strip down and have a 100 people stare at you?

Since Propositional and Lexical sarcasm are difficult to be distinguished, example (2) might look like Propositional sarcasm. However, Camp explains that "lexical sarcasm tends to employ an expression at the extreme end of an evoked scale" (2011, 27). In the case of example (10) above, 
'great' as a stronger scale of good, is inverted with 'awful' or 'terrible'.

As Lexical sarcasm has a stronger connection to an evoked evaluative scale than Propositional sarcasm, the extreme adjective said by the speaker aims to emphasize the targeted evaluative expression. Therefore, in the case of example (10), Sue expresses her evaluation of Reed's idea which has disgraced her in front of many people by emphasizing that it is not only bad, but even terrible. In addition, the use of 'great ideas' also contradicts with the whole illocutionary force in Sue's utterance, because 'strip down and have 100 people stare' is clearly not a great idea at all. Thus, Sue's first sentence might seem sincere for asking someone's idea, but then the second sentence made it sound as a verbal assault to the hearer.

\section{Like-Prefixed Sarcasm}

Like-Prefixed sarcasm is the second least frequently used type after Lexical sarcasm, with only three occurrences (12,5\%). This type of sarcasm targets an entire proposition of an utterance, and it combines with declarative sentence (Camp, 2011, p. 27). When a sarcastic expression is prefaced with 'like', it indicates that the speakers aim to perform their denial to the content. Below are two examples of the use of this type of sarcasm.

00:44:04,600 - 00:44:08,230 (F1.LP.01.Col)

Reed, Ben, Johnny and Sue are moving in to Reed's apartment to research their new powers. Before they get in to the elevator, Reed receives his apartment bills which have not been paid for nine years, and Sue accidentally sees them.

Reed: (To Sue) We had a tough year.

Ben: Yeah, like nine straight.

In example (11), we can obviously see how Ben pretends to agree with Reed that they have 'one' tough year. He commits that as if nine years is the same with one tough year that Reed mentions. Ben's utterance can clearly be seen as a sarcastic denial to his proposition and indicates that they have been struggling with the bills for a long time.
As explained before, like-prefixed sarcasm is only felicitous when it is combined with declarative sentence. However, an utterance prefixed with 'like' that might seem to be a question can also be understood as this type, as long as its illocutionary force asserts some proposition. Camp and Hawthorne (2008, p. 4) present the following example

\section{(12) Like you are going to do the dishes?}

which cannot be heard as having an interrogative force because it aims to evince the skepticism that the hearer might clean the dishes. Thus, the example from the first movie below can also be considered as like-prefixed sarcasm even though it is uttered with a syntactic structure of a question.

(13) 01:04:38,280 - 01:04:52,593 (F1.LP.02.Com)

Johnny is making a scene by exposing his team to the public and gives his friends names without thinking about the risk. Reed, Sue, and Ben scold him because they did not know how long their power will last or what will happen to them.

Reed: You need to control yourself and think before you act.

Johnny: Yeah, but see, that's your problem. You always think, you never act. What if we got these powers for a reason? What if it's like some higher calling?

Reed: A higher calling? Like getting girls and making money?

Johnny: Is there any higher?

In addition, Reed responds to Johnny's argument of why he acts childishly by pointing out what he has been doing in a sarcastic way. Reed's utterance cannot also be considered as a question because his intention is to assert a proposition and assault Johnny.

Moreover, Camp and Hawthorne explain that one of the differences between like-prefixed and bare sarcasm is that sarcastic 'Like' and 'As if' license Negative Polarity Items, while bare sarcasm does not (2008, p. 6). Rizea (2017, p. 2) states:

Negative Polarity Items are single words or multi-word expressions that 
prototypically occur in the scope of negation, but also in other contexts that are semantically or pragmatically interpreted as negative.

Camp and Hawthorne (2008) also present the following examples:

(14a) It's not true that I was going to give him any money.

(14b) I was not going to give him any money

(14c) $\{$ Like/As if $\}$ I was going to give him any money

(14d) \# I was going to give him any money

We can learn that in intending (26a), it is difficult to understand (26d) as a sarcastic utterance no matter how scornful the tone might be. Thus, the prefix 'Like' in (26c) is needed to consider the utterance as sarcasm. In short, the prefix 'Like' or 'As if can be invisible in the speaker's sarcastic utterance, but it actually exists. The same case also happens in the utterance below:

$$
\text { 01:28:12,280 - 01:28:22,114 (F1.LP.03.Col) }
$$

After Victor gets more power, he kidnaps, and tortures Reed in his building. Then, Sue and Ben come to save him.

Ben: Victor ain't that bad, huh. "He's just a little larger than life, right?" Maybe next time you'll listen to me before...

In example (15), Ben is quoting Reed's statement about Victor who is not really a bad person, which he has said before when Ben does not want to work together with him. Ben clearly intends to show that Reed is wrong, because turns out, Victor becomes worse than what they have expected. Therefore, we can see his denial when saying "Victor ain't that bad" and his intention to scorn Reed. Moreover, as explained before, LikePrefixed sarcasm licenses Negative Polarity Items, the prefix 'Like' of this utterance can be seen by the identification below:

(16a) It is not true that Victor ain't that bad

(16b) Victor is a bad person

(16c) $\{$ Like/As if $\}$ Victor ain't that bad
This identification shows that to say Ben's denial of what he says, the prefix 'Like' is used as a feature to mark the sarcasm.

\section{Propositional Sarcasm}

Camp (2011) states that propositional sarcasm is the most straightforward type. This sarcasm is the opposite of what a sincere utterance is supposed to be (p. 21). The most important aspect of this type is that the speakers make a negation of a certain preposition and say the opposite of what they really mean. This type can be found in a form of sentences, phrases, and sometimes only a single adjective. Below is an example of the use of propositional sarcasm taken from one of the movies.

00:26:58,075 - 00:27:05,957 (F2.Pro.05.Col)

Reed and Sue are having a wedding, but in the middle of the ceremony, Reed's machine detects a danger and disturbs the wedding's process. This makes Sue mad because her wedding does not turn to something that she has always been dreaming of.

Sue: I can't believe you brought that to our wedding.

Reed: I know, but there's a good reason. We have to do this quickly.

Sue: That's romantic.

This example shows that Sue expresses her feeling sarcastically in a straightforward way, by saying something that is the opposite of what she really means. If the context of that situation is not clear, Sue's utterance might be seen sincere and truthful. However, the context of that dialogue gives us enough information about Sue's disappointment at the unpleasant thing that Reed does, because Reed's bringing his machine to their wedding disturbs the wedding process, and Reed's asking the priest to skip the vow is not romantic at all. Hence, the negation can be detected easily in this utterance. The same is true with the following example:

00:04:31,120 - 00:04:35,714 (F1.Pro.01.Col)

Reed is coming to Victor's office to present his research project and asks his cooperation. They both went to the same 
university, but Reed was such a smart student and made other students, including Victor, felt inferior and jealous. Thus, Victor gets cocky knowing that he becomes more successful than Reed, who finally comes to ask for help. Moreover, he also gets Reed's girlfriend, which makes him even more jealous.

Victor: It's funny how things turn out, isn't it?

\section{Reed: Hilarious.}

As mentioned above, propositional sarcasm can be found even in a single adjective. This dialogue might not be clear if we do not know the context and the background relationship between the speaker and the hearer. Reed realizes that how things turn out for both of them might be funny for Victor, but not for him. Therefore, when he says that it is hilarious in his pathetic condition, he only pretends to agree with Victor, rather than seriously means what he says.

However, the example below is not as clear as the previous ones.

00:09:40,160 - 00:10:01,390 (F1.Pro.02.Col)

Reed and his team are in a space ship and get ready to start their research. Then, Johnny assumes that Reed was trying to fix his relationship with Sue, and he does not think that it is a good idea.

Johnny: Please tell me you guys not trying to rekindle things with my sister again.

Ben: Of course not. It's strictly business.

Johnny: Yes, well, his eyes say differently, don't they?

Ben: Two hearts got busted last time. Maybe she's not over it, either.

Johnny: Wow, Dr. Phil, that's deep. Let's think about that. You got Victor, more money than God, stud of the year. And you got Reed, world's dumbest smart guy, worth less than a postage stamp.

To understand the sarcasm in example (19), we have to consider a community membership as a common ground. This means that "the interlocutors take as common ground everything they believe is universally known in the community where they both belong" (Clark, Schreuder, and Buttrick, 1983, p. 247). Therefore, when Johnny mentions about "Dr. Phil", it refers to a famous American TV Show named Dr. Phil. He believes that as the same community member as Ben, which is American, they both share the common understanding about who Dr. Phil is.

Further, Camp states that in every case of propositional sarcasm, the targeted proposition $P$ is associated with some evaluative scale, and the speaker implicates the contrary of $P$ with respect to that scale, along with correlative evaluative attitude toward Q (2011, p. 21). Johnny's allusion evokes a scale of intelligence and wisdom, because Dr. Phil's host, Phillip Calvin McGraw, is widely known for having those traits as a psychologist. Johnny pretends to claim that Ben was being wise and advisable, while in fact he implicated the opposite. It can be seen from Johnny's theory, "Let's think about that.....", which is against Ben's argument and showed that Ben's statement did not make sense. Hence, in this case, Johnny mentions "Dr. Phil" as an allusion to give the verbal aggression to Ben for being the opposite of Phil's factual characteristics.

\section{The Functions of Sarcasm}

Since there is no specific theory which analyzes the functions of sarcasm, this research adopts Leech's categorization of illocutionary functions of utterances. Leech (1983, p. 104) argues that illocutionary functions can be classified into four according to the social goal of creating and preserving politeness to the interlocutor: competitive, convivial, collaborative and conflictive. Based on this categorization, it was found that eight (32\%) sarcastic utterances were used to express the competitive function, three $(12 \%)$ to express the convivial function, 14 (56\%) to express the collaborative function, and no sarcastic utterance is used to express the conflictive function. Table 2 below presents the frequency and distribution of the functions of sarcasm in the movies. 
Table 2. The frequency and distribution of the illocutionary functions of sarcasm in the movies

\begin{tabular}{clrr}
\hline No. & Functions & Number & \multicolumn{2}{c}{$\%$} \\
\hline 1. & Collaborative & 14 & 56 \\
\hline 2. & Competitive & 8 & 32 \\
\hline 3. & Conflictive & 0 & 0 \\
\hline 4. & Convivial & 3 & 12 \\
\hline & Total & 25 & 100 \\
\hline
\end{tabular}

\section{Collaborative Function}

It can be seen from the table above that the collaborative function is the most frequently used function in the movies (56\%). This suggests that the characters in the movies tend to use sarcastic utterances for collaborative purposes to maintain politeness. Nevertheless, Leech (1983, p. 104) argues that the objective of this function is indifferent with the social goal, where politeness is mainly irrelevant within the speech acts performed, such as asserting, reporting, announcing, instructing, etc. Therefore, the utterances which have the collaborative function can be neither polite nor impolite. Below is an example of the use of this function:

$$
\text { 00:54:56,120 - 00:55:07,753 (F1.Ill.06.Col) }
$$

Reed is doing a research to study his team's power after they are hit by the cosmic radiation, and he asks everybody to not go into public. Then, when Sue is taking a walk, she finds out that her team has become famous after people see their power on television.

Sue: Reed, we really can't go outside anymore. We are on the cover of every publication from...

\section{Johnny: All right, I'm here, let's make this quick. I got a lot of places to go today. Oh, wait. I don't go anywhere.}

Johnny's utterance above is used to scorn Reed's decision to forbid them from going outside. He sarcastically declares that he is not going anywhere, while what he really wants to say is that he needs to go outside and have fun like he always does. In this case, Johnny's sarcastic expression is uttered as indifferent as possible, but it still can make the hearer consider it as a verbal assault.

\section{Competitive Function}

Leech (1983, p. 104) states that the illocutionary goal of this function is to compete with the social goal, for instance: ordering, asking, demanding, begging, etc. The purpose of the competitive goal is to reduce the dissonance between what the speaker wants and what is good manner. However, this function is considered as impolite, and the speaker needs to lessen the impoliteness of the goal.

It was found that eight sarcastic utterances (32\%) were used to express this function, all of which are expressed in interrogative forms. As sarcasm causes an assault effect to the hearer, the purpose of asking a question to express evaluation toward some attitudes can minimize its harm for the hearer. Such a question do not demand an answer since it is performed as an evaluation, but sometimes when the hearers realize that they are being criticized and disagree with it, their answer would be correlated with the speaker's true intention. The dialogue between Ben and Johnny below is presented as an example of the use of the competitive function:

$$
\text { 00:31:33,183 } \rightarrow \text { 00:31:47,238 (F2.Ill.12.Com) }
$$

After Silver Surfer ruins Reed's wedding, Johnny tries to catch him. They both get into a fight, but Johnny loses because Silver Surfer is much stronger than him. Then, he reports to the team that their enemy looks strange, but then Ben makes fun of him.

Johnny: It looked like a man, but completely covered in silver, and it flew this, like...surfboard-type thing. I know that sounds crazy.

\section{Ben: Oh, no, not at all. Did you follow the shiny man to Lollipop Land or the Rainbow Junction?}

There is an incongruity between Ben's first and second utterance in this example. At first, he says that he does not agree with Johnny who thinks that what he says is crazy, but the question 
clearly shows the opposite and implies that Johnny's explanation does not make any sense. In short, what Ben really means is that Johnny is talking nonsense and it all sounds crazy. Nevertheless, Ben has mitigated the damage of his true intention by performing this indirect approach, because declaring his disbelief explicitly might cause Johnny to feel even worse.

\section{Convivial Function}

This type of function is contradictory with the previous one. Leech (1983) states that the acts which belong to convivial, e.g. offering, inviting, greeting, thanking, and congratulating are considered as courteous. These speech acts are performed by using opportunities for being polite. For instance, when $\mathrm{A}$ has an opportunity to offer help to B who is carrying big heavy stuff, then A should do so, because the illocutionary goal of the convivial function coincides with the social goal. (pp. 104-105). However, although the true intention of the sarcasm produced cannot be understood as polite at all, the speech given by the speaker still holds the convivial function. On the other hand, it was also found that the convivial function is rarely used in the movies, with only three occurrences. This shows that the characters in the movies do not really take the opportunities to show their courtesy as pretense in expressing sarcasm. Below is one example of the use of this function:

\section{0:23:14,560 - 00:23:29,636 (F1.Ill.03.Conv)}

As Reed's best friend, Ben knows that Reed is still in love with Sue, but does not have any courage to make a move. Finally, he sets them up on a dinner, but Ben suddenly feels sick because of the radiation's reaction and has to leave them in an awkward moment.

Reed: So, you feeling better?

Sue: Yes, thank you.

Reed: Good. That's...good.

\section{Sue: You always had a way with words.}

According to McGraw-Hill Dictionary of American Idioms and Phrasal Verbs, 'have a way with words' is an idiom which means "to have talent in the effective or stylish use of words".
This idiom is used as a compliment for someone who has a good ability in using words nicely. However, the context shows that Reed does not have such a talent, and Sue is expressing sarcasm through this compliment. Even though Leech (1983) does not categorize what function a compliment belongs to, Shabeeb \& Jibran (2008, p. 9-10) state that compliments belong to the convivial class, as they also coincide with the social goal.

\section{CONCLUSION}

In this study, as many as 25 sarcastic expressions were found in the two American movies, Fantastic Four (2005) and Fantastic Four: Rise of the Silver Surfer (2008), which run for a total of 198 minutes. This means that the characters produce one sarcastic expression every 7.92 minutes in the movies. This figure is slightly lower than those reported by Prabowo (2013) and Wulandari (2017). In his research, Prabowo (2013) found one sarcastic expression every 5.67 minutes and Wulandari one every 2.69 minutes. It is interesting to note, however, that both investigated British movies, whereas the present research examines American movies. This seems to suggest that British people tend to be more sarcastic than American people. As Leech argues, in term of manners, American tend to be more direct to express themselves than British (1983, p. 231). For that reason, it is understandable if Americans do not use sarcasm as much as British people do. If this is true, then cultural backgrounds seem to play an important role in the production of sarcasm.

As more than half of the sarcastic expressions in this research belong to illocutionary sarcasm, we can say that people in the movies are likely to express the opposite attitude of what the sincere utterance would have been performed. The speakers of illocutionary sarcasm also perform the illocutionary force of a speech act that would have been appropriate to be said in the opposite situation. While in term of maintaining politeness, the result shows that half of the sarcastic utterances ignore the social goal of their illocutionary force. 
It was also found that in identifying whether an utterance is sarcastic or not, a clear context is needed. Moreover, the interlocutors have to share some adequate common ground in employing sarcasm to avoid misunderstanding. It is also found that even though sarcasm is naturally intended to scold the addressee, it can mitigate the impact of what a literal expression would cause.

\section{REFERENCES}

Austin, L. J. (1962). How to do things with words. Oxford: Clarendon Press.

Bowes, A. \& Katz, A. (2011). When sarcasm stings. Discourse Processes, 48(4), 215-236. https://dx.doi.org/10.1080/0163853X.2010.5 32757.

Brant, W. (2012). Critique of sarcastic reason. Saarbrücken, Germany: Südwestdeutscher Verlag für Hochschulschriften.

Cahyani, E.H. (2017). A study of sarcasm in the American sitcom The big bang theory Unpublished undergraduate thesis. Yogyakarta: Sanata Dharma University. Retrieved from https://repository.usd.ac.id/ 12909/2/131214086_full.pdf.

Camp, E. (2011). Sarcasm, pretense, and the semantics/pragmatics distinction. Nous, 46(4), 1-48. https://doi.org/10.1111/j.14680068.2010.00822.x.

Camp, E., \& Hawthorne, J. (2008). Sarcastic 'like': A case study in the interface of syntax and semantics. Philosophical Perspectives, 22(1), 1-21. https://doi.org/10.1111/j.15208583.2008.00140.x.

Caucci, G., \& Kreuz, R. (2012). Social and paralinguistic cues to sarcasm. International Journal of Humor Research, 25(1), 1-22. https://doi.org/10.1515/humor-2012-0001.

Cheang, H. S., \& Pell, M. D. (2008). The sound of sarcasm. Speech Communication, 50(5), 366-381.doi: 10.1016/j.specom.2007.11.003

Clark, H. H. (1992). Arenas of language use. Chicago: The University of Chicago Press.

Clark, H. H., Schreuder, R., \& Buttrick, S. (1983). Common ground and the understanding of demonstrative reference. Journal of Verbal
Learning and Verbal Behavior, 22, 245-258. https://doi.org/10.1016/S00225371(83)90189-5

Cutting, J. (2002). Pragmatics and discourses. London: Routledge.

Dews, S., Kaplan, J., \& Winner, E. (1995). Why not say it directly? The social functions of irony. Discourse Processes, 19(3), 347-367. https://dx.doi.org/10.1080/016385395095449 22.

Fantastic Four. (n.d.). Retrieved January 19, 2018, from https://subscene.com/subtitles/ fantastic-four/english/1068625).

Fantastic Four: Rise of the Silver Surfer. (n.d.). Retrieved January 19, 2018, from (https://subscene. com/subtitles/fantastic-four-rise-of-thesilver-surfer/english/1380265).

Haiman, J. (1998). Talk is cheap : Sarcasm, alienation, and the evolution of language. USA: Oxford University Press.

Have a way with words. (n.d.). In McGraw-Hill dictionary of American idioms and phrasal verbs. Retrieved from https://idioms. thefreedictionary.com/have+a+way+with+ words.

Joshi, A., Bhattacharyya, P. \& Carman, M. J. (2017). Automatic sarcasm detection: A survey. $A C M, 50(5)$. https://doi.org/10.1145/3124420.

Leech, G. (1983). Principles of Pragmatics. New York: Longman.

McDonald, S. (1999). Exploring the process of inference generation in sarcasm: A review of normal and clinical studies. Brain and Language, 68(3), 486--506.

Minchin, E. (2010). The expression of sarcasm in the Odyssey. Mnemosyne, 63(4), 533-556.

Prabowo, M.S. (2013). Sarcastic expressions in the movie The Guard. Unpublished undergraduate thesis. Yogyakarta: Universitas Gadjah Mada. Retrieved from http://etd.repository.ugm.ac.id/index.php?m od=penelitian_detail\&sub=PenelitianDetail 
\&act=view\&typ=html\&buku_id=66881\&oby ek_id $=4$.

Rizea, M.-M. (2017). Closer to the truth? Strong negative polarity items between controlled diagnostic environtments and eeal-use distribution profiles from large corpora. Romania: Bucharest University Press.

Sarcasm. (n.d.). In Merriam-Webster online dictionary. Retrieved from https://www.merriam-webster.com/ dictionary/sarcasm

Shaheeb, M., \& Jibreen, K. (2008). The speech act of compliment: A theoretical view. Journal of Al-Qadisiya University, 11(4), 9-10.

Story, T. (Director), \& Avi, A., \& Eichinger., \& Winter. R. (Producers). (2005). Fantastic four [Motion Picture on VCD], Indonesia: PT. Inova Digimedia

Story, T. (Director), \& Avi, A., \& Eichinger., \& Winter. R. (Producers). (2008). Fantastic four: Rise of the silver surfer [Motion Picture on VCD], Indonesia: PT. Inova Digimedia
Tepperman, J., Traum, D., \& Narayanan, S. (2006). Yeah right: Sarcasm recognition for spoken dialogue systems. Ninth International Conference on Spoken Language Processing (1838-1841). Pittsburgh: University of Southern California.

Wulandari, L. O. (2017). Sarcastic Expressions Used by Charlie Wyman in the movie Letters to Juliet. Unpublished undergraduate thesis. Yogyakarta: Universitas Gadjah Mada. Retrieved from http://etd.repository. ugm.ac.id/index.php?mod=penelitian_detail \&sub=PenelitianDetail\&act=view\&typ $=\mathrm{html}$ \&buku_id=109015\&obyek_id=4.

Yule, G. (1996). Pragmatics. Oxford: Oxford University Press. 